Original Research

\title{
Distribusi Nepenthes spp. di Hutan Kalampangan
}

\author{
Lasmitha Dewi ${ }^{1,2, *}$, Agus Haryono ${ }^{2}$, Yohanes E. Gunawan ${ }^{2}$ \\ ${ }^{1}$ SMPN 1 Satu Atap Tanah Siang Selatan, Kabupaten Murung Raya, Kalimantan Tengah \\ 2 Program Studi Magister Pendidikan Biologi Universitas Palangka Raya \\ * Korespondensi: Lasmitha Dewi (Email: lasmithadewi.ld@gmail.com)
}

Diterima: 05 April 2020

Direvisi: 15 Juni 2020

Disetujui: 22 Juni 2020

\begin{abstract}
Kalampangan peat swamp forests in Central Kalimantan is home for Nepenthes spp. However, the number of Nephentes has been reduced due to massive forest fires and land conversion for housing and agricultural purposes. Nepenthes is a unique plant with ability to prey insects, hence often referred to as 'insectivorous plant'. This study investigates the distribution of Nepenthes spp. in Kalampangan forest through ground check and qualitative descriptive approach. A total of six observation plots measuring of $2 \mathrm{~m} \times 2 \mathrm{~m}$ were used purposively. The results show there are four Nepenthes species found, namely Nepenthes gracilis, Nepenthes mirabilis, Nepenthes gracilis cortis, and Nepenthes ampularia. The highest Morisita index is 1.06 while the lowest one is 1.01 .
\end{abstract}

\section{Keywords}

Nephentes spp, distribution, Kalampangan, peat swamp forest, Morisita index

\section{PENDAhUluAN}

Nepenthes adalah tumbuhan yang memiliki kantong pada ujung daunnya. Kantong Nepenthes memiliki berbagai bentuk, ukuran, dan warna yang beranekaragam sehingga menarik untuk dilihat. Kantong ini adalah modifikasi daun, terbentuk untuk meningkatkan efisiensi perolehan unsur hara yang dibawa oleh air hujan. Keunikan dari Nepenthes ini, kantong yang tumbuh dari ujung daun dapat membuat serangga dan beberapa hewan-hewan lainnya terperangkap di dalamnya. Namun ada juga beberapa serangga yang tetap mampu bertahan hidup dalam cairan yang terdapat pada kantong Nepenthes seperti jentik nyamuk. Seiring terjadinya pembalakan hutan, Nepenthes menjadi salah satu tumbuhan yang jarang ditemukan dan populasinya di alam semakin berkurang (Mansur, 2007). Kebutuhan nutrisi Nepenthes spp. akan nitrogen begitu besar sehingga selain dari tanah, tumbuhan ini memperoleh nutrisi dari sumber lain seperti serangga, sehingga keberadaan serangga sangat diperlukan Nepenthes (Akhriadi dan Hernawati, 2006).

Kalampangan merupakan salah satu habitat Nepenthes spp. di Kalimantan Tengah yang termasuk hutan rawa gambut. Hutan ini merupakan area mega proyek lahan sejuta hektar yang telah dibuka 12 tahun yang lalu yang direncanakan untuk lahan pertanian khususnya padi yang terletak kurang lebih $30 \mathrm{~km}$ dari Palangka Raya. Namun demikian masih tersisa hutan yang tidak dibuka untuk lahan dan pembangunan rumah (Mansur, 2006). Akibat kebakaran hutan dan alih fungsi pembukaan lahan sebagai perumahan ataupun lahan pertanian yang menyebabkan keberadaan Nepenthes semakin berkurang.

Nepenthes yang telah ditemukan di Kalimantan sebanyak 31 jenis dan 24 jenis lainnya berstatus endemik (Clarke, 2001). Dewantara dan Ardian (2018) mencatat bahwa di Kalimantan Tengah terdapat tiga jenis tumbuhan Nepenthes yang paling sering ditemukan yaitu Nepenthes ampullaria, Nepenthes gracilis, Nepenthes rafflesiana, sedangkan menurut Mansur (2008) di daerah Sabangau, Kereng Bangkirai, terdapat empat jenis tumbuhan Nepenthes yang terdiri dari 4 spesies yaitu Nepenthes gracilis, Nepenthes rafflesiana, Nepenthes ampullaria dan Nepenthes xhookeriana. Menurut Denik (2016), di Taman Nasional Sebangau Resort Habaring Hurung, Nepenthes spp. yang diperoleh ada sebanyak tiga jenis yaitu Nepenthes mirabilis, Nepenthes rafflesiana dan Nepenthes gracilis. Penelitian ini perlu dilakukan sebelum tumbuhan Nepenthes di alam benar-benar punah, selain itu juga karena seluruh jenis Nepenthes merupakan tumbuhan yang dilindungi maka dari iti morfologi dan distribusi Nepenthes pada Hutan Kalampangan perlu dilakukan penelitian. 


\section{METODOLOGI}

Penelitian pendekatan deskriptif kualitatif dengan metode survei. Pengamatan dilakukan selama 3 bulan, dari Mei 2019-Juli 2019. Lokasi Penelitian adalah Hutan Kalampangan, Kelurahan Kalampangan, Kecematan Sebangau, Kota Palangka Raya. Peralatan laboratorium yang digunakan dalam proses penelitian yaitu meteran, aplikasi GPS (Global Position System) Map Camera, gunting, tali, penggaris. Metode yang digunakan dalam penelitian ini adalah metode survey dengan teknik pengambilan data jelajah atau eksplorasi (Santoso dan Tjiptono, 2000). Setiap jenisdan individu dari tumbuhan Nepenthes yang ditemukan sepanjang penjelajahan akan dilakukan penandaan titik koordinat menggunakan alat Camera Global Positioning System (GPS) Maps untuk data distribusi tumbuhan. Tumbuhan Nepenthes yang ditemukan diamati ciri-ciri morfologi untuk diidentifikasi. Data dari hasil penelitian tumbuhan Nepenthes di Hutan Kalmpangan dimasukkan ke dalam tabel pengamatan yang terdapat nama spesies, karakter morfologi, titik koordinat, dan jumlah Nepenthes yang ditemukan. Tahapan penelitian terdiri dari tiga tahap, yaitu tahap persiapan, tahap penelitian dan analisis data. Berikut merupakan uraian kegiatan yang dilakukan pada masing-masing tahap:

\section{Tahap Persiapan}

Tahap persiapan merupakan tahap yang dilakukan sebelum tahap penelitian atau kegiatan pengambilan data. Tahap ini dilaksanakan pada bulan November 2019. Tahap ini terdiri dari studi literatur, survey lapangan, dan persiapan alat dan bahan penelitian. Pada tahap studi literatur, semua informasi mengenai tumbuhan Nepenthes seperti morfologi, keragaman, dan distribusi Nepenthes spp. Pada tahap survei lapangan dilakukan pengamatan lokasi penelitian, penentuan jalur transek dengan model petak lapangan seperti pada gambar 1 .

$(2 \mathrm{~m})$

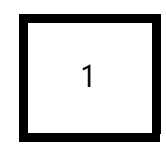

$(2 \mathrm{~m})$

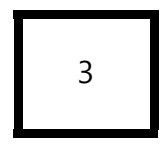

$(2 \mathrm{~m})$

$(2 \mathrm{~m})$

$(2 \mathrm{~m})$
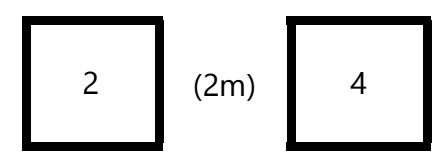

$(2 \mathrm{~m})$

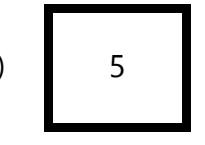

$(2 \mathrm{~m})$

Gambar 1. Plot penelitian

2. Tahap Penelitian

Pengambilan data terdiri dari jenis tumbuhan Nepenthes, jumlah cacah individu tumbuhan Nepenthes, titik koordinat ditemukannya tumbuhan Nepenthes, dan distribusi Nepenthes. Identifikasi jenis tumbuhan Nepenthes dilakukan dengan cara didokumentasikan menggunakan kamera handphone dan pengamatan langsung karakter morfologi tanaman yang terdiri dari batang, kantong Nepenthes (bentuk, warna, tinggi kantong, dan bentuk bibir kantong), daun (panjang, lebar dan warna daun), dan bunga. Titik koordinat ditemukannya tumbuhan Nepenthes diambil menggunakan Camera Global Positioning System (GPS) Maps kemudian dicatat.

\section{Analisis Data}

Selanjutnya dilakukan identifikasi tumbuhan Nepenthes Informasi mengenai karekteristik morfologi yang telah diperoleh kemudian diidentifikasi dan dibandingkan dengan informasi jenis Nepenthes yang telah ada dari literatur seperti jurnal, buku, hasil penelitian yang berkaitan dengan jenis tumbuhan Nepenthes maupun herbarium untuk menentukan jenis dan nama ilmiah tumbuhan Nepenthes yang diperoleh selama penelitian. Buku yang digunakan untuk mengidentifikasi jenis tumbuhan Nepenthes adalah: Ensiklopedia Flora Jilid 3, Sudarmono (2009). Data penelitian ini dianalisis untuk mengetahui Distribusi Nepenthes dengan menggunakan Indeks Morisita $(I \delta)$. Indeks Morisita $(I \delta)$ tidak dipengaruhi oleh luas stasiun pengambilan sampel dan sangat baik untuk membandingkan pola penyebaran

$$
I \delta=\frac{\mathrm{n} X \mathrm{i}(X \mathrm{X}-1)}{\mathrm{N}(\mathrm{N}-1)}
$$

Keterangan:
$I \delta \quad=\quad$ Indeks Morisita
$\mathrm{N}=$ Jumlah seluruh individu dalam total $\mathrm{n}$
$\mathrm{n}=$ Jumlah seluruh plot pengambilan sampel
$\mathrm{Xi}=$ Jumlah Kantong Semar per plot

\section{HASIL DAN PEMBAHASAN}

Hasil identifikasi Nepenthes spp. yang ditemukan di Hutan Kalampangan diperoleh sebanyak 4 Nepenthes, yaitu Nepenthes gracilis, Nepenthes mirabilis, Nepenthes gracilis kort, dan Nepenthes ampularia.

Gambar 2 menunjukan tumbuhan Nepenthes gracilis yang memiliki bentuk batang segitiga, daun berbentuk lanset, tipis sampai agak tebal. Kantong spesies ini berbentuk silindris dan memiliki. Bunga berbentuk tandan dengan warna coklat muda sampai coklat tua. Nepenthes gracilis relatif masih mampu tumbuh pada tanah terbuka bila masih terdapat lapisan serasah tipis yang menutupi permukaan akarnya. Nepenthes gracilis pada kondisi cahaya penuh beradaptasi dengan kondisi kumpulan rumpunnya tumbuh dengan rapat, sehingga permukaan akarnya dapat tertutupi oleh kumpulan rumpun batang, daun dan kantong yang tumbuh rapat dan jumlah yang besar. Kondisi seperti itu membuat Nepenthes gracilis tumbuhnya pendek dengan ukuran batang, daun dan 


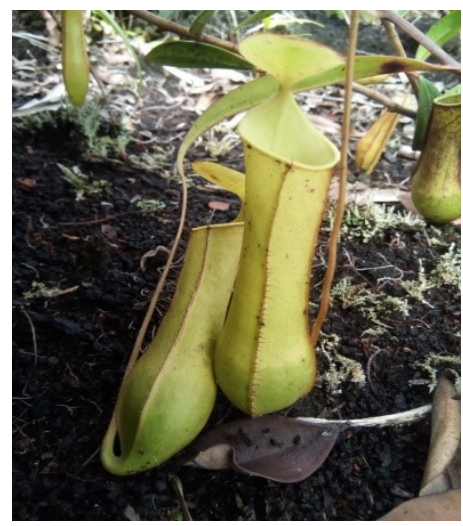

(a)

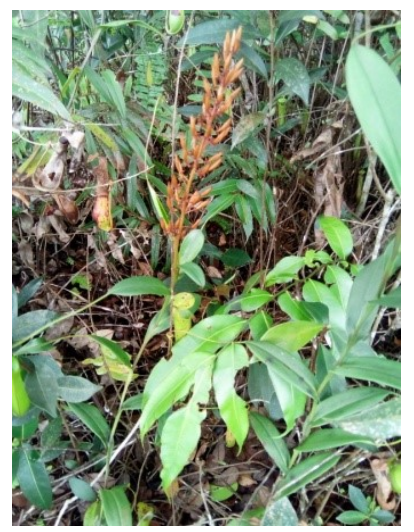

(b)

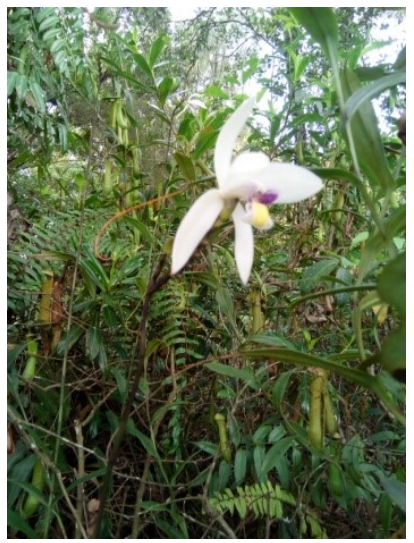

(c)

Gambar 2. Nepenthes gracillis

(a) Kantong atas, (b) Bunga pada Nepenthes, (c) Nepenthes dan serangga

kantong yang relatif kecil dibandingkankan Nepenthes gracilis yang permukaan akarnya tertutup serasah dan dinaungi kumpulan tumbuhan tingkat pancang dan semai. Fenomena ini diduga selain berhubungan dengan siklus air dalam Nepenthes gracilis juga berhubungan dengan input nutrisi yang berasal dari kumpulan serasah yang telah terdekomposisi terutama sumber Nitrogen. Kelimpahan jumlah individu Nepenthes gracilis relatif tinggi pada daerah gambut yang terbuka dan memiliki lapisan gambut atau serasah yang tipis. Nepenthes gracilis banyak ditemukan di kawasan yang memiliki kandungan hara pada daerah tersebut relatif rendah dan banyak mengandung asam-asam organik yang menyebabkan tumbuhan Nepenthes gracilis tumbuh.

Sementara itu, Gambar 3 adalah tumbuhan Nepenthes mirabilis yang memiliki bagian sulur memanjang dengan tinggi mencapai $3 \mathrm{~m}$, dengan bentuk kantong Nepenthes batang bulat, licin, dan kuat dengan ruas-ruas Nepenthes yang jelas. Daun pada tumbuhan roset pendek tidak bertangkai-tangkai. Panjang tangkai daun 1 hingga $3 \mathrm{~cm}$.
Daun berbentuk lanset, kadang-kadang bulat panjang dengan panjang 10 hingga $23 \mathrm{~cm}$ dan lebar 1,2 hingga 2,9 $\mathrm{cm}$, ujung runcing atau meruncing, pinggir daun berambut, tulang tepi sebanyak 3 hingga 5 pada masing-masing sisi daun. Sulur panjangnya 6 hingga $13 \mathrm{~cm}$, mempunyai bulubulu halus. Kantong pada daun roset bagian bawah berbentuk seperti mangkok lalu menyempit sedikit sampai ke atas, tinggi $6 \mathrm{~cm}$, panjang daun 8 hingga $15 \mathrm{~cm}$ dengan lebar 1,2 hingga 4,5 cm.

Pengamatan terhadap variasi warna daun ditemukan lima variasi. Variasi tersebut terletak pada perbedaan warna permukaan atas helaian daun, permukaan bawah helaian daun, permukaan atas tulang daun primer, dan permukaan bawah tulang daun primer. Warna-warna helaian daun yang ditemukan adalah hijau, hijau dengan becak-becak kekuningan, dan merah tua dengan bintikbintik kehitaman. Sementara itu, warna-warna tulang daun primer adalah hijau, hijau kekuningan, kuning muda, hijau dengan becak-becak keunguan, kuning, merah cerah, merah hati, dan kuning kemerahan.

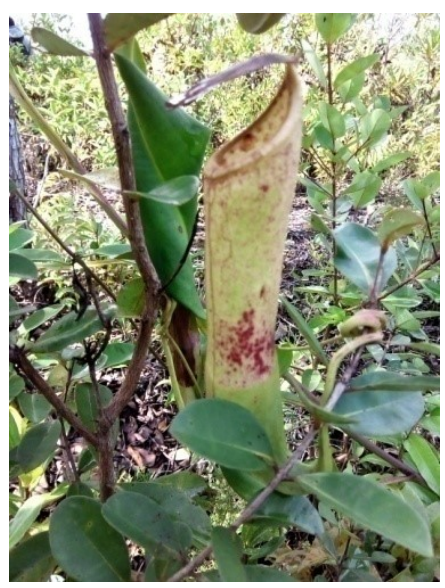

(a)

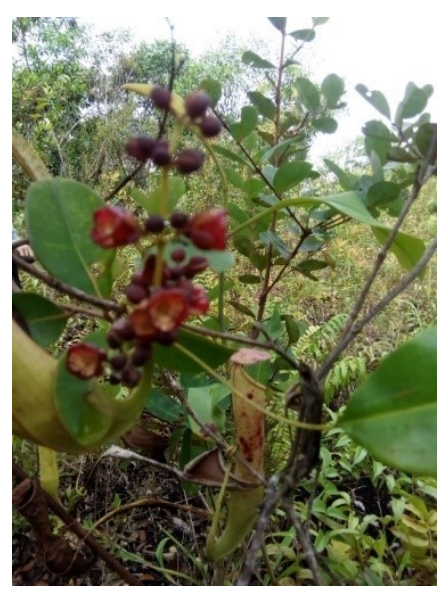

(b)

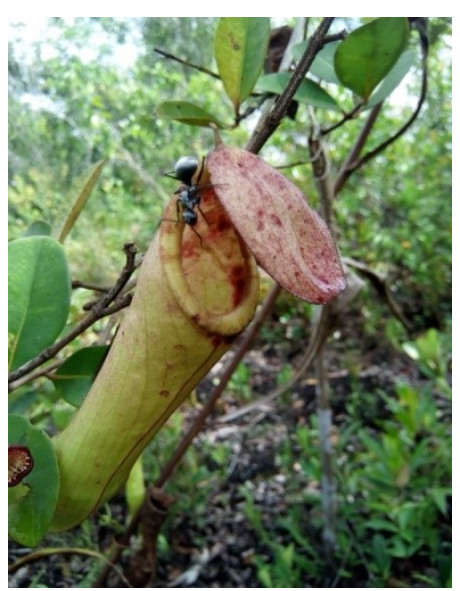

(c)

Gambar 3. Nepenthes mirabilis. (a) Kantong atas, (b) Bunga pada Nepenthes, (c) Nepenthes dan serangga 


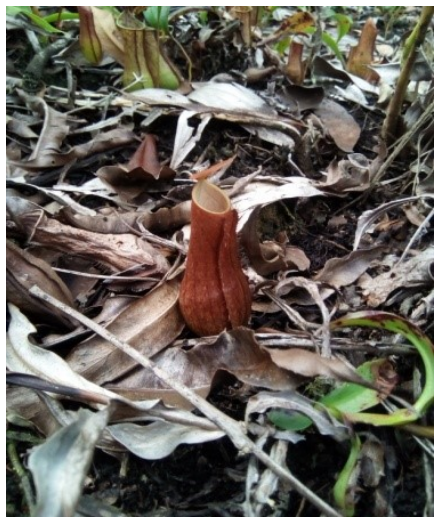

(a)

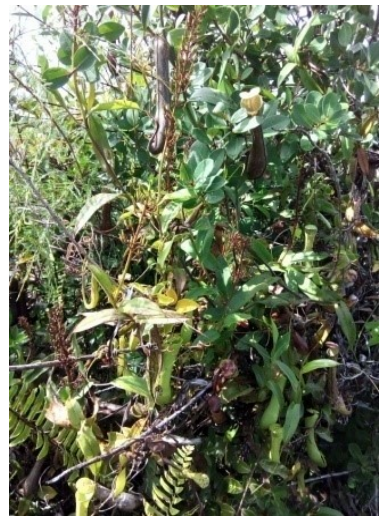

(b)

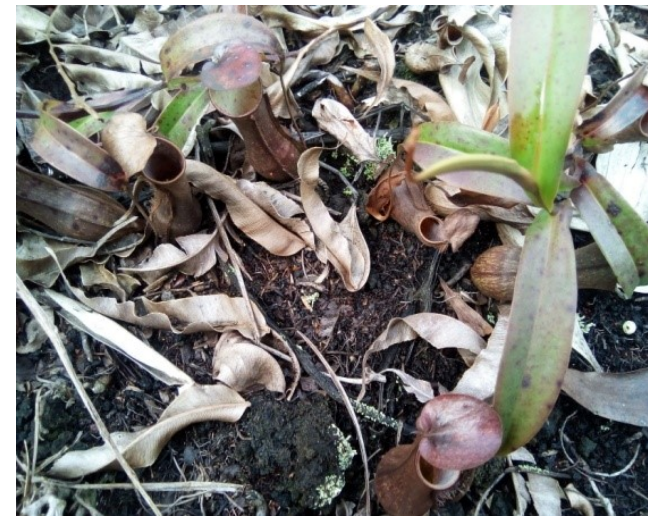

(c)

Gambar 4. Nepenthes gracilis kort. (a) Kantong bawah, (b) Bunga pada Nepenthes, (c) Kumpulan Nepenthes

Gambar 4 adalah Nepenthes gracilis kort. juga ditemukan pada areal terbuka dan ternaungi. Pertumbuhan Nepenthes gracilis kort. menempel dan merambat pada batang atau cabang pohon lain yang hidup didekatnya dan ada juga yang hidup terrestrial di atas permukaan tanah gambut. Kantong bagian bawah Nepenthes gracilis kort. memiliki dua sayap, berbentuk oval, kantong atas berbentuk slinder, tinggi lebih kurang $9 \mathrm{~cm}$, lebar 2,5 cm, berwarna hijau, merah pekat atau terkadang cokelat kemerah-merahan. Bunga berbentuk tandan dengan warna coklat tua dengan panjang $26,7 \mathrm{~cm}$. Nepenthes gracilis kort. memiliki daya adaptasi tinggi terhadap berbagai intensitas cahaya dan kondisi lingkungan yang miskin unsure hara.

Nepenthes gracilis kort hidup sebagai tumbuhan liana, maka tumbuhan ini dapat hidup dengan baik secara bergerombol dan menggunakan sulur untuk tetap mencapai cahaya matahari yang dibutuhkan. Nepenthes gracilis kort. yang tumbuh di area terbuka memiliki ukuran daun yang lebih lebar dan berwarna lebih hijau dibandingkan yang tumbuh di area tenaung. Di lokasi penelitian Nepenthes gracilis kort. lebih banyak ditemukan pada area terbuka dibandingkan area ternaungi. Nepenthes gracilis kort. yang ditemukan cenderung pada pola penyebaran secara bergerombol dimana individu-individu selalu ada dalam kelompok-kelompok dan sangat jarang terlihat sendiri secara terpisah.

Umumnya Nepenthes gracilis kort mempunyai pola penyebaran yang mengelompok. Pola penyebaran yang mengelompok tersebut maka terdapat interaksi yang saling menguntungkan antar individu. Nepenthes gracilis kort ditemukan pada hutan tertutup dan hutan terbuka.

Gambar 5 adalah Nepenthes ampullaria termasuk dalam Nepenthes kantong bawah yang memiliki tinggi 5-7 $\mathrm{cm}$ dengan diameter lingkaran $6 \mathrm{~cm}$. Memiliki bulu-bulu halus pada bagian permukaan kantong dan mampu hidup di area hutan terbuka. Nepenthes ini ditemukan pada hutan gambut. Karakteristik hutan gambut yang miskin hara sangat sesuai dengan habitat yang dibutuhkan oleh kantong semar pada umumnya. Namun pada hutan gambut terdapat juga jenis Nepenthes ampullaria, walaupun jenis Nepenthes ini masih sulit ditemukan di habitat rawa gambut lainnya. Pola sebaran Nepenthes ampullaria secara umum bersifat mengelompok pada kedua tipe habitat hutan gambut tertutup dan hutan gambut terbuka. Nepenthes ampullaria tumbuh mengelompok dengan kapadatan tinggi pada habitat terbuka seperti hutan sekunder dan hutan gambut.Pengelompokkan juga disebabkan karena individu

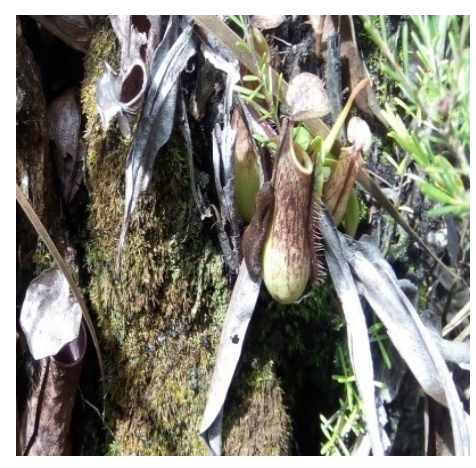

(a)

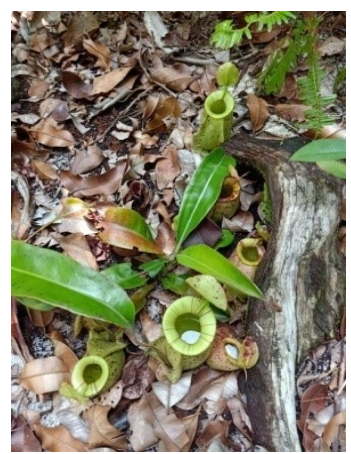

(b)

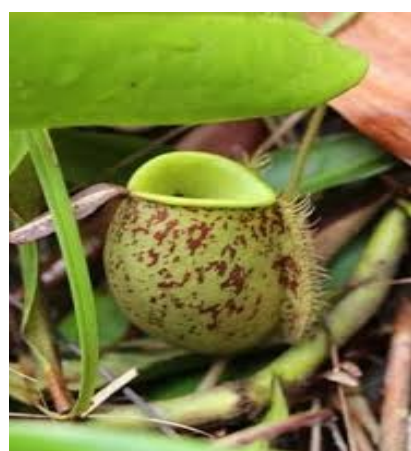

(c)

Gambar 5. Nepenthes ampularia. (a) Kantong bawah, (b) Nepenthes roset, (c) gambar pembanding 
Tabel 1. Penyebaran Nepenthes spp di Hutan Kalampangan

\begin{tabular}{|c|c|c|c|c|}
\hline No & Plot & Titik Koordinat & Indeks Morista & Pola Penyebaran \\
\hline 1. & 1 & 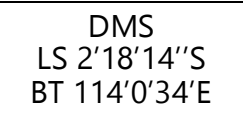 & 1,03 & Bergerombol \\
\hline 2. & II & $\begin{array}{c}\text { DMS } \\
\text { LS 2'18'37"S } \\
\text { BT } 114^{\prime} 0^{\prime} 28^{\prime \prime} \mathrm{E}\end{array}$ & 1,05 & Bergerombol \\
\hline 3. & III & 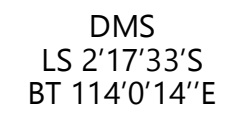 & 1,02 & Bergerombol \\
\hline 4. & IV & $\begin{array}{c}\text { DMS } \\
\text { LS } 2^{\prime} 18^{\prime} 55^{\prime \prime S} \\
\text { BT } 114^{\prime} 0^{\prime} 28^{\prime \prime} E\end{array}$ & 1,02 & Bergerombol \\
\hline 5. & V & $\begin{array}{c}\text { DMS } \\
\text { LS 2'17'47"S } \\
\text { BT } 114^{\prime} 025^{\prime \prime} E\end{array}$ & 1,06 & Bergerombol \\
\hline 6. & $\mathrm{VI}$ & 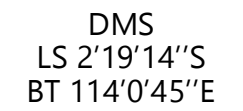 & 1,01 & Bergerombol \\
\hline
\end{tabular}

memiliki kecenderungan untuk berkumpul dan mencari kondisi lingkungan yang sesuai dengan kebutuhan hidupnya. Bentuk morfologi dan sifat pertumbuhan dari Nepenthes spp. menjadi faktor pendukung terjadinya pola penyebaran baik secara acak, bergerombol maupun seragam.

Indeks Morista menunjukkan cara untuk mengetahui penyebaran suatu jenis tumbuhan pada suatu habitat. Hasil penelitian ini menunjukkan bah wa pada 6 plot pengamatan di Hutan Kalampangan ditemukan pola penyebaran dalam kategori bergerombol. Indeks Morisita tertinggi, yaitu sebesar 1,06 terdapat pada plot $\mathrm{V}$ dititik LS 2'17'47'S dan BT 114'025'E sedangkan Indeks Morisita terendah, yaitu sebesar 1,01 terdapat pada plot VI di titik LS 2'19'14"S dan BT 114'0'45"E.

\section{KESIMPULAN}

Berdasarkan pengecekan di lapangan disimpulkan bahwa terdapat empat jenis Nephentes di hutan Kalampangan, yaitu Nepenthes gracilis, Nepenthes mirabilis, Nepenthes gracilis kort, dan Nepenthes ampularia, dengan distribusi Nepenthes tidak merata pada setiap plot. Indeks Morisita tertinggi, yaitu sebesar 1,06 terdapat pada plot $\mathrm{V}$ dititik LS 2'17'47'S dan BT 114'025'E sedangkan Indeks Morisita terendah, yaitu sebesar 1,01 terdapat pada plot VI di titik LS 2'19'14"S dan BT 114'0'45"E.

\section{DAFTAR PUSTAKA}

Akhriadi, P., Hernawati. 2006. A field guide to the Nepenthes of Sumatera. Padang: PILI-NGO Movement.

Clarke, C., 2001. Nepenthes of Sumatra and peninsular Malaysia. Natural History Publications (Borneo).

Dewantara, I. and Ardian, H., 2018. Keanekaragaman Jenis Kantong Semar (Nepenthes spp) di Kebun Raya Sambas Kecamatan Subah Kabupaten Sambas Kalimantan Barat. Jurnal Hutan Lestari, 6(3), 519-525.

Denik, S., 2016. Studi Keanekaragaman Jenis Kantong Semar Nepenthes Sp. dan Serangga yang Terjebak di Dalamnya di Taman Nasional Sebangau Resort Habaring Hurung. Digital Library. Palangka Raya.

Mansur, M., 2006. Nepenthes, Kantong Semar Yang Unik. Jakarta: Penebar Swadaya.

Mansur, M., 2007. Keanekaragaman jenis Nepenthes (kantong semar) dataran rendah di Kalimantan Tengah. Berita Biologi, 8(5), 335-341.

Mansur, M., 2008. Penelitian ekologi Nepenthes di laboratorium alam hutan gambut Sabangau kereng bangkirai Kalimantan Tengah.Jurnal Teknologi Lingkungan, 9(1), 63-73.

Masita, 2005. Pola Penyebaran Pohon Cendana (Santalum album L) di Taman Hutan Raya Palu. Skripsi. Fakultas Pertanian Universitas Tadulako. Tidak dipublikasikan.

Santoso, S. and Tjiptono, F., 2000. Buku Latihan SPSS Statistik Parametrik. Jakarta: Elex Media Komputindo, Kelompok Gramedia.

Suhono. B., Yuzammi, Witono, J.R., Hidayat, S., Handayani, T., Sugiarti, Mursidawati, S., Triono, T., Astuti, I.P., Sudarmono. 2010. Ensiklopedia Flora. Bogor: Kharisma IImu. 